\title{
Circulating microRNAs are elevated in plasma from severe preeclamptic pregnancies
}

\author{
Liang $\mathrm{Wu}^{1,2}$, Honghui Zhou ${ }^{3}$, Haiyan Lin ${ }^{1}$, Jianguo $\mathrm{Qi}^{1}$, Cheng Zhu ${ }^{1}$, Zhiying Gao ${ }^{3}$ and \\ Hongmei Wang ${ }^{1}$
}

${ }^{1}$ State Key Laboratory of Reproductive Biology, Institute of Zoology, Chinese Academy of Sciences, 1 Beichen West Road, Chaoyang District, Beijing 100101, People's Republic of China, ${ }^{2}$ Graduate School, Chinese Academy of Sciences, Beijing 100039, People's Republic of China and ${ }^{3}$ Department of Obstetrics and Gynecology, PLA General Hospital, Beijing 100853, People's Republic of China

Correspondence should be addressed to H Wang; Email: wanghm@ioz.ac.cn, Z Gao; Email: gaozy301@yahoo.com.cn

\begin{abstract}
Until recently, the molecular pathogenesis of preeclampsia (PE) remained largely unknown. Reports have shown that circulating microRNAs (miRNAs) are promising novel biomarkers for cancer, pregnancy, tissue injury, and other conditions. The objective of this study was to identify differentially expressed miRNAs in plasma from severe preeclamptic pregnancies compared with plasma from normal pregnancies. By mature miRNA microarray analysis, 15 miRNAs, including 13 up- and two downregulated miRNAs, were screened to be differentially expressed in plasma from women with severe PE (sPE). Seven miRNAs, namely miR-24, miR-26a, miR-103, miR-130b, miR-181a, miR-342-3p, and miR-574-5p, were validated to be elevated in plasma from severe preeclamptic pregnancies by real-time quantitative stem-loop RT-PCR analysis. Gene ontology and pathway enrichment analyses revealed that these miRNAs were involved in specific biological process categories (including regulation of metabolic processes, regulation of transcription, and cell cycle) and signaling pathways (including the MAP kinase signaling pathway, the transforming growth factor- $\beta$ signaling pathway, and pathways in cancer metastasis). This study presents, for the first time, the differential expression profile of circulating miRNAs in sPE patients. The seven elevated circulating miRNAs may play critical roles in the pathogenesis of $\mathrm{SPE}$, and one or more of them may become potential markers for diagnosing sPE.
\end{abstract}

Reproduction (2012) 143 389-397

\section{Introduction}

Preeclampsia (PE), a pregnancy-related disease characterized by hypertension and proteinuria, is a major cause of maternal mortality, morbidities, perinatal deaths, preterm birth, and intrauterine growth restriction (Sibai et al. 2005). Although circulating soluble fmslike tyrosine kinase 1 , soluble endoglin, and placental growth factor were recently suggested to contribute to the pathogenesis of PE (Levine et al. 2006), the mechanisms involved in this pathological condition remain poorly understood.

MicroRNAs (miRNAs) are a conserved group of $\sim 22-$ nucleotide regulatory RNAs that play important roles in regulating gene expression by binding to $3^{\prime}$-UTR of mRNAs for either degradation or translation repression (Bartel 2004). miRNAs have been shown by oligonucleotide microarrays to be highly enriched in the placenta (Barad et al. 2004). However, miRNAs are differentially expressed in the human placentas of patients with PE, which indicates that miRNAs may have important roles in the pathogenesis of PE. In one report, among the 157 miRNAs manipulated by realtime quantitative RT-PCR (qRT-PCR) analysis, the expression of two miRNAs (miR-182 and miR-210) was significantly increased (2.1- and 3.0-fold respectively) in placentas of PE patients compared with that in women with normal pregnancy (Pineles et al. 2007). In addition, gene ontology $(\mathrm{GO})$ analysis of the potential target genes of miR-182 and miR-210 indicated that specific biological process categories (anti-apoptosis for miR182 and regulation of transcription for miR-210) were enriched (Pineles et al. 2007). A microarray analysis of 836 known human mature miRNAs in placental tissues of PE patients identified 91 dysregulated miRNAs, including 38 down- and 53 upregulated miRNAs (Roman et al. 2008). Two other reports (Hu et al. 2009, Zhu et al. 2009) further proved the importance of miRNAs in the pathophysiology of PE. Zhu et al. (2009) demonstrated that 11 miRNAs (including miR-210 and miR-181a) were overexpressed in the placentas of PE patients, whereas the levels of 23 miRNAs were 
decreased compared with women with normal pregnancies. The elevation of miR-181a in preeclamptic placentas was also identified by another group ( $\mathrm{Hu}$ et al. 2009). In other studies, miRNAs specifically expressed in human placentas were detected in sera from pregnant women and found to be significantly elevated compared with those from nonpregnant women; their levels increased with gestational age and decreased after delivery, providing a new group of molecular markers for pregnancy monitoring (Chim et al. 2008, Gilad et al. 2008). In this study, a microarray analysis of the miRNA expression profile in plasma from severe PE (sPE) and normal pregnancies, as well as a realtime qRT-PCR validation, was performed to explore the association between maternal circulating miRNAs and the molecular pathogenesis of sPE.

\section{Results \\ miRNA microarray analysis}

To investigate whether maternal circulating miRNAs are associated with the pathogenesis of sPE, plasma samples were collected from women with normal pregnancies and pregnancies complicated by SPE. A comprehensive miRNA microarray analysis was performed on nine plasma samples, including five sPE plasma samples and four plasma samples from normal pregnancies. Among the 821 human miRNAs detected by microarray, 15 differentially expressed miRNAs were identified, of which 13 miRNAs, namely miR-574-5p, miR-26a, miR-151-3p, miR-130a, miR-181a, miR-130b, miR30d, miR-145, miR-103, miR-425, miR-221, miR-342$3 p$, and miR-24, were upregulated in sPE plasma samples and two miRNAs, namely miR-144 and miR16, were downregulated in SPE plasma samples, compared with those from normal pregnancies $(P<0.05$, twofold changes or more). As shown in Fig. 1, among all 15 dysregulated miRNAs, the fold changes of miR-574-5p and miR-26a appeared to be more pronounced.

\section{miRNA expression validation by real-time quantitative stem-loop RT-PCR analysis}

Real-time stem-loop qRT-PCR was performed to validate the 15 differentially expressed miRNAs identified in the miRNA microarray analysis. Nineteen plasma samples, consisting of ten sPE plasma samples and nine normal plasma samples, were used for RNA isolation with the mirVana PARIS kit. As shown in Fig. 2, seven miRNAs, namely miR-24, miR-26a, miR-103, miR-130b, miR181a, miR-342-3p, and miR-574-5p, were validated to be elevated in sPE plasma samples. Consistent with miRNA microarray analysis, the changes of all seven elevated miRNAs were either two- or threefold.

\section{GO and pathway enrichment analyses}

GO analysis of the predicted targets of the seven elevated miRNAs indicated that a large group of genes was connected to chromatin/nucleic acid/protein/ion binding, regulation of metabolic processes, regulation of transcription, embryonic development, and cell cycle (Table 1). Pathway enrichment analysis suggested that several pathways, including long-term potentiation, endocytosis, the transforming growth factor-beta (TGF- $\beta$ ) signaling pathway, cytokine-cytokine receptor interaction, the MAP kinase (MAPK) signaling pathway, and pathways in cancer metastasis, were mostly related to the seven significantly elevated miRNAs (Table 2).

\section{Discussion}

Circulating miRNAs have emerged as potential novel diagnostic biomarkers for cancer (Mitchell et al. 2008), pregnancy (Chim et al. 2008, Gilad et al. 2008), tissue injury (Wang et al. 2009), and other conditions. PE is a critical pregnancy-specific disease complicated by hypertension and proteinuria, and is a major cause of maternal mortality, morbidities, perinatal deaths, preterm birth, and intrauterine growth restriction (Sibai et al. 2005), affecting $3-5 \%$ of pregnancies worldwide

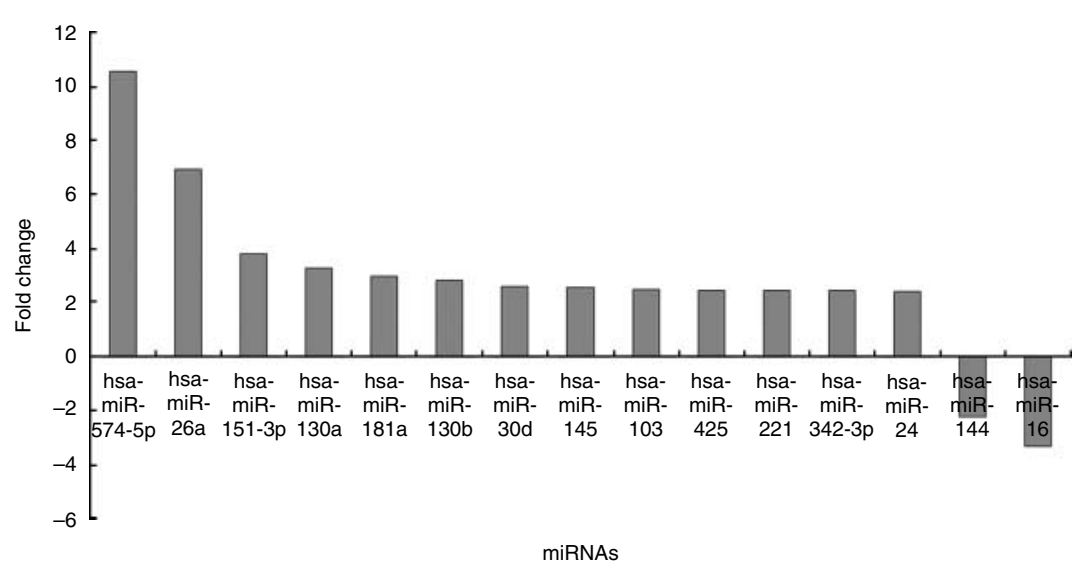

Reproduction (2012) 143 389-397

\begin{abstract}
Figure 1 Differential expression profile of miRNAs in human plasma by miRNA microarray. Nine samples, including five sPE plasma samples and four normal pregnancy plasma samples, were analyzed by Agilent miRNA microarray chips. The expressions of 15 miRNAs were screened to be significantly $(P<0.05)$ differential (twofold changes or more), of which 13 were upregulated and two were downregulated. The baseline denotes the mean expression level of miRNAs in four plasma samples from normal pregnancy.
\end{abstract}




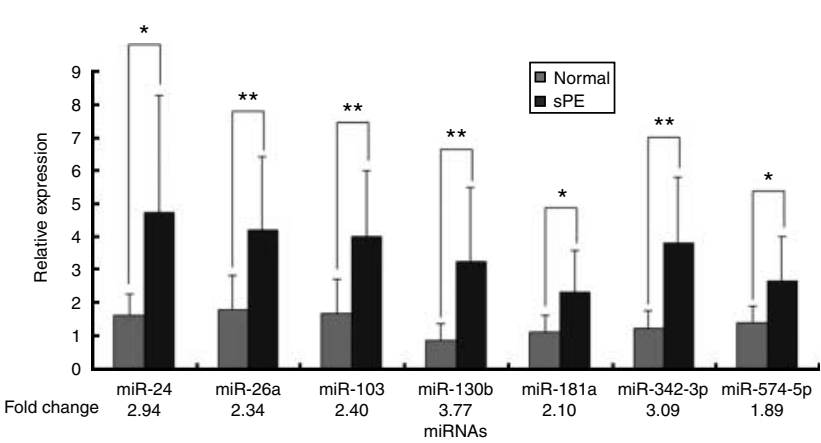

Figure 2 Expressions of miRNAs were validated by real-time quantitative stem-loop RT-PCR analysis. Synthetic C. elegans miRNAs, including cel-miR-39, cel-miR-54, and cel-miR-238, were added to normalize variation in RNA isolation from different samples. The experimental real-time qRT-PCR values were normalized by these three spiked-in C. elegans control miRNAs. Bar graphs show real-time qRTPCR analysis of miR-24, miR-26a, miR-103, miR-130b, miR-181a, miR-342-3p, and miR-574-5p in human plasma samples from sPE $(n=10)$ and normal pregnancies $(n=9)$. The data are presented as relative expression following normalization. The columns denote the mean; the bars denote the S.D. ${ }^{*} P<0.05$ and ${ }^{* *} P<0.01$.

(Hogberg 2005). The mechanisms involved in PE remained poorly understood, despite advances in our understanding of this pathological condition (Levine et al. 2006). Exploration of the roles of differentially expressed circulating miRNAs in PE patients will enrich our understanding of the pathogenesis of this disease and contribute to its diagnosis and management. This study, for the first time, has profiled the differential expression of miRNAs in plasma samples from pregnant women with sPE compared with those from women with normal pregnancies. Seven miRNAs, namely miR-24, miR-26a, miR-103, miR-130b, miR-181a, miR-342-3p, and
miR-574-5p, were found to be elevated significantly in sPE plasma samples.

Abnormal placentation is one of the major pathological causes of PE (Myatt 2002), and delivery of the placenta remains the only definitive treatment for $\mathrm{PE}$ (Maynard et al. 2008). Several reports (Pineles et al. 2007, Roman et al. 2008, Hu et al. 2009, Zhu et al. 2009, Enquobahrie et al. 2011, Mayor-Lynn et al. 2011, Noack et al. 2011) have illustrated the differential expression of placental miRNAs in PE patients. However, except for miR-210 (elevated in preeclamptic placenta) (Pineles et al. 2007, Zhu et al. 2009, Enquobahrie et al. 2011), miR-181a (elevated in preeclamptic placenta) (Hu et al. 2009, Zhu et al. 2009), and miR-1 (decreased in preeclamptic placenta) (Roman et al. 2008, Zhu et al. 2009, Enquobahrie et al. 2011), there was little overlap among these data; this could have resulted from differences in the sample collections (including the gestational ages of the placentas and the processing of the placentas), profiling methods and patients' ethnicities (Hu et al. 2009). Interestingly, in this study, miR181 a was also validated to be elevated in plasma samples from sPE patients. miR-181a is one member of the hsa-miR-181 family (Ji et al. 2009) that also includes miR-181b, miR-181c, and miR-181d. miR-181a has been shown to be an intrinsic modulator of $\mathrm{T}$ cell sensitivity and selection; the inhibition of miR-181a expression in immature $T$ cells decreased their sensitivity to antigen and weakened both positive and negative selection (Li et al. 2007), indicating its critical role in establishing proper development of immunity and tolerance, which are largely involved in placentation (Sibai et al. 2005, Bonney 2007). Since posttranscriptional silencing of $30 \%$ of protein-coding genes in

Table 1 Gene ontology analysis of circulating miRNAs elevated in SPE.

\begin{tabular}{|c|c|c|c|c|c|c|c|}
\hline \multirow[b]{2}{*}{ Biological process category $(n)$} & \multicolumn{7}{|c|}{ Genes targeted by miRNAs } \\
\hline & miR-24 & miR-26a & miR-103 & miR-130b & miR-181a & miR-342-3p & miR-574-5p \\
\hline Anatomical structure morphogenesis & 23 & & 20 & & 25 & 7 & \\
\hline Binding & & 168 & 121 & & 164 & & \\
\hline Biosynthetic process & & & & 53 & 67 & 17 & \\
\hline Cell communication & 54 & & & & & & 9 \\
\hline Cell cycle & & 19 & 14 & 15 & & & \\
\hline Cellular component organization & & 42 & 35 & & & & \\
\hline Cellular developmental process & 26 & & 22 & & & & \\
\hline Chromatin binding & & & 4 & & 5 & & 2 \\
\hline Embryonic development & 13 & & 13 & & 13 & 6 & \\
\hline Ion binding & & & 51 & & 64 & & \\
\hline Nucleic acid binding & & & 39 & 45 & 56 & & \\
\hline Nucleoside-triphosphatase regulator activity & & 11 & 10 & 13 & & & \\
\hline Positive regulation of biological process & 29 & & & 32 & & 11 & \\
\hline Positive regulation of cellular process & 27 & & & 29 & & 10 & \\
\hline Protein binding & & 113 & 92 & 93 & 119 & 26 & \\
\hline Regulation of cellular process & 91 & 99 & 69 & & 101 & & \\
\hline Regulation of metabolic process & 46 & & 40 & 52 & 63 & & \\
\hline Transcription factor activity & & & 15 & 16 & 21 & & \\
\hline Transcription regulator activity & & & 24 & 25 & 27 & & \\
\hline Transport & & 48 & 39 & & & & \\
\hline
\end{tabular}

Values represent the number of genes targeted by miRNAs. 
Table 2 Pathway enrichment analysis of circulating miRNAs elevated in SPE.

\begin{tabular}{|c|c|c|c|c|c|c|}
\hline \multirow[b]{2}{*}{ Pathway $(n)$} & \multicolumn{6}{|c|}{ Genes targeted by miRNAs } \\
\hline & miR-24 & $\operatorname{miR}-26 a$ & miR-103 & miR-130b & miR-181a & miR-342-3p miR-574-5p \\
\hline Long-term potentiation & 2 & 2 & & 2 & 2 & 3 \\
\hline Endocytosis & 3 & & 4 & 5 & 4 & \\
\hline TGF- $\beta$ signaling pathway & & & 2 & 3 & 3 & 3 \\
\hline Adipocytokine signaling pathway & & 2 & & 2 & 3 & \\
\hline Cytokine-cytokine receptor interaction & 4 & & & 4 & 4 & \\
\hline Glycerophospholipid metabolism & 4 & & & 2 & 4 & \\
\hline MAPK signaling pathway & 8 & 7 & & & & 5 \\
\hline Pathways in cancer metastasis & 6 & & 4 & 6 & & \\
\hline Regulation of actin cytoskeleton & & 4 & 3 & 3 & & \\
\hline Vascular smooth muscle contraction & 3 & 4 & & & 3 & \\
\hline SODD/TNFR1 signaling pathway & & 1 & 1 & & 2 & \\
\hline Adherens junction & & & 2 & & 3 & \\
\hline Calcium signaling pathway & 4 & & & & 4 & \\
\hline Gap junction & 2 & & & 3 & & \\
\hline MTOR signaling pathway & & 2 & & 3 & & \\
\hline PPAR signaling pathway & & & & 2 & 2 & \\
\hline Wnt signaling pathway & & 3 & & 3 & & \\
\hline ErbB signaling pathway & 2 & & & 2 & & \\
\hline CDK regulation of DNA replication & 1 & 1 & & & & \\
\hline Mechanism of protein import into the nucleus & 1 & 1 & & & & \\
\hline $\begin{array}{l}\text { Role of PI3K subunit p85 in regulation of actin } \\
\text { organization and cell migration }\end{array}$ & 1 & & & & & 2 \\
\hline p53 signaling pathway & & 2 & & & 2 & \\
\hline Dicer pathway & & & 1 & 1 & & \\
\hline
\end{tabular}

Values represent the number of genes targeted by miRNAs.

mammals were shown to be mediated by miRNAs (Lewis et al. 2005), the increased expression of miRNAs in $\mathrm{SPE}$ patients could have a profound impact on diverse biological functions (Table 1).

In addition to miR-181a, six other miRNAs, namely miR-24, miR-26a, miR-103, miR-130b, miR-342-3p, and miR-574-5p, were also found to be elevated in sPE plasma samples. These miRNAs, with the exception of miR-574-5p, which has been poorly investigated, had all been identified to be ubiquitously expressed in 40 normal human tissues, including brain, heart, kidney, liver, lymph node, and placenta (Liang et al. 2007). Since $\mathrm{PE}$ is a multisystem disorder, and several factors including renal disease, obesity and insulin resistance, and maternal susceptibility genes, have been identified with increased risk of PE (Sibai et al. 2005), further exploration of the sources of these significantly elevated circulating miRNAs in human tissues, especially in placenta due to its possible importance in the pathogenesis of $\mathrm{PE}$, is needed.

The enrichment for specific biological process categories, including regulation of metabolic processes, regulation of transcription, and cell cycle, were revealed by the GO analysis of the predicted target genes of the seven elevated miRNAs (Table 1). Consistently, significant metabolism abnormalities in severe preeclamptic placenta have been found since the late 1980s, including metabolisms of glycogen, amino acids, and lipids (Bloxam et al. 1987, Walsh \& Wang 1993). The placenta is also relatively hypoxic in $\mathrm{PE}$, since the differentiation of cytotrophoblast is abnormal and the invasion (including interstitial invasion and endovascular invasion) is shallow (Genbacev et al. 1996). Hypoxia inducible factor 1 (HIF1), a transcriptional activator consisting of a constitutively expressed HIF1 $\beta$ subunit and an $\mathrm{O}_{2}$-regulated HIF1 $\alpha$ subunit, is an important global regulator of oxygen homeostasis (Semenza \& Wang 1992, Wang et al. 1995). Under hypoxic conditions, HIF1 $\alpha$ binds to the constitutively expressed HIF1 $\beta$, and the complex subsequently translocates to the nucleus and binds to the HIF-responsive elements, initiating and enhancing the transcription of a series of genes counteracting hypoxia, which include increase in glucose uptake, activation of glycolysis, the kidney synthesis of erythropoietin, and angiogenesis stimulation (Tranquilli \& Landi 2010). The expression of HIF1 $\alpha$ has been reported to be upregulated in preeclamptic placentas obtained by cesarean section (Rajakumar et al. 2004). And a specific group of miRNAs, including miR-24, miR-26a, miR-103, and miR-181a, which were all found to be elevated in SPE plasma samples in this study, were revealed to be also elevated via a key involvement of HIF in human cancer cell lines, in response to low oxygen (Kulshreshtha et al. 2007). Besides, a very recent study reported that the miR-130 family members, including miR-130a and miR-130b, the latter of which was also found to be upregulated in SPE plasma samples in this study, regulated HIF1 $\alpha$ signaling via targeting P-body protein DDX6, which promoted the translation of HIF1 $\alpha$ under hypoxia (Saito et al. 2011). In 
addition, it has long been believed that cytotrophoblast proliferation is upregulated in low oxygen concentrations (Fox 1964), which is further supported by the phenomenon that there are increased numbers of cytotrophoblast cells in the placenta at high altitude (Ali 1997), indicating the cell cycle is altered in preeclamptic placenta. However, more investigation is required to determine the mechanisms whereby the seven circulating miRNAs were elevated in SPE.

The results of pathway enrichment analysis suggested that these seven elevated miRNAs were involved in several pathways, including the MAPK signaling pathway, the TGF- $\beta$ signaling pathway, and pathways in cancer metastasis. Consistent with the prediction shown in Table 2, miR-24 was reported to be able to stimulate MAPK signaling by directly targeting MAPK phosphatase 7 (Zaidi et al. 2009). miR-24 was also involved in TGF- $\beta$ signaling, since miR-24 could repress erythropoiesis by directly targeting activin type I receptor ALK4 and subsequently interfering with activin-induced SMAD2 phosphorylation (Wang et al. 2008).

All the seven elevated miRNAs presented in this study have been identified to be involved in the pathways in cancer metastasis. The miR-103/107 miRNA family was recently identified as a negative regulator of miRNA biosynthesis by targeting Dicer, which is a critical member of the miRNA-processing machinery; this resulted in decreased miR-200 expression, which induced epithelial-to-mesenchymal transition (Martello et al. 2010). miR-130b was shown to be involved in cell growth and self-renewal by directly targeting tumor protein 53-induced nuclear protein 1 (Yeung et al. 2008, Ma et al. 2010), and cancer metastasis (Su et al. 2010). Despite the fact that miR-342-3p, miR-574-5p, miR-26a, and miR-181a were not included in the pathways in cancer metastasis by pathway enrichment analysis (Table 2), these four miRNAs also had critical roles in cancer metastasis. miR-342-3p has been suggested as a potential marker for prion disease (Saba et al. 2008), multiple myeloma (Ronchetti et al. 2008), and breast cancer (Van der Auwera et al. 2010). miR-574-5p was recently reported to be significantly associated with chemoresistance in patients with small cell lung cancer (Ranade et al. 2010). miR-26a was recently found to greatly decrease the expression of $E Z H 2$, which resulted in the inhibition of cell growth and tumorigenesis of nasopharyngeal carcinoma (Lu et al. 2011). Conversely, $E Z H 2$ expression could be elevated through negative modulation of its repressor miR-26a by MYC (Sander et al. 2008), which had been demonstrated to be directly targeted by miR-24 via binding to seedless miRNA recognition elements within its $3^{\prime}$-UTR (Lal et al. 2009). miR-181a has recently been identified as an oncogenic miRNA in MCF-7 cells (Oliveras-Ferraros et al. 2011).

In summary, through miRNA microarray assay and real-time stem-loop qRT-PCR analysis, this study demonstrated a maternally differential circulating miRNA expression profile in plasma samples from severe preeclamptic pregnancies compared with those from normal pregnancies. The relationship between sPE and dysregulated miRNA expression suggests critically functional roles of miRNAs in the pathology of this pregnancy-related disease. These differentially expressed miRNAs might be novel targets for the further investigation of the molecular pathogenesis and management of sPE. However, due to the high biological variability of human plasma samples, a study with a larger number of samples, which also profiles gestation from an early stage, is needed to prove miRNA analysis as an ideal and easily accessible diagnostic method for PE.

\section{Materials and Methods}

\section{Sample collection}

Plasma samples were obtained with informed consent from patients with late-onset sPE (sPE group; $n=10$ ) and termmatched normal pregnancies (control group; $n=9$ ); all pregnancies were between 37 and 40 weeks of gestation. All women were patients at the Department of Obstetrics and Gynecology, General Hospital of the People's Liberation Army in Beijing, China. A woman was determined to have sPE when either severe hypertension (either a systolic blood pressure of $160 \mathrm{mmHg}$ or higher or a diastolic blood pressure of $110 \mathrm{mmHg}$ or higher on two occasions at least $6 \mathrm{~h}$ apart while the patient was on bed rest) or severe proteinuria (either urinary excretion of $5 \mathrm{~g}$ protein or higher in a $24 \mathrm{~h}$ urine specimen or $3+$ protein or greater in two random urine samples collected at least $4 \mathrm{~h}$ apart), or both, were present after 20 weeks of gestation (Practice ACoO 2002). All women with

Table 3 Demographic and clinical characteristics of normal and severe preeclamptic pregnancies.

\begin{tabular}{|c|c|c|c|}
\hline Characteristics & Control $(n=9)$ & $\mathbf{s P E}(n=10)$ & $P$ value \\
\hline Maternal age (years) & $30.4 \pm 1.3$ & $29.9 \pm 3.1$ & NS \\
\hline Current smoker $(n)$ & $0(0 \%)$ & $0(0 \%)$ & \\
\hline $\begin{array}{l}\text { Preeclampsia onset } \\
\text { (weeks) }\end{array}$ & None & $34.4 \pm 1.8$ & \\
\hline Complicated by SGA $(n)$ & None & $3(30 \%)$ & \\
\hline $\begin{array}{l}\text { Gestational age at } \\
\text { delivery (weeks) }\end{array}$ & $38.8 \pm 0.4$ & $37.7 \pm 1.0$ & NS \\
\hline Primiparae $(n)$ & $9(100 \%)$ & $9(90 \%)$ & \\
\hline Birth weight (g) & $\begin{array}{c}3510.0 \pm \\
482.7\end{array}$ & $\begin{array}{c}2964.3 \pm \\
567.7\end{array}$ & NS \\
\hline Female fetus $(n)$ & $5(55.6 \%)$ & $5(50 \%)$ & \\
\hline Prepregnancy weight $(\mathrm{kg})$ & $55.2 \pm 6.1$ & $62.2 \pm 8.0$ & NS \\
\hline $\begin{array}{l}\text { Prepregnancy body mass } \\
\text { index }\left(\mathrm{kg} / \mathrm{m}^{2}\right)\end{array}$ & $20.5 \pm 2.6$ & $23.3 \pm 3.4$ & NS \\
\hline Han ethnicity $(n)$ & $9(100 \%)$ & $10(100 \%)$ & \\
\hline Proteinuria (g/24 h) & Normal & $3.3 \pm 3.2$ & $<0.01$ \\
\hline $\begin{array}{l}\text { Systolic blood pressure } \\
(\mathrm{mmHg})\end{array}$ & $112.0 \pm 4.5$ & $161.1 \pm 15.4$ & $<0.01$ \\
\hline $\begin{array}{l}\text { Diastolic blood pressure } \\
\quad(\mathrm{mmHg})\end{array}$ & $70.0 \pm 0$ & $105.0 \pm 13.2$ & $<0.01$ \\
\hline
\end{tabular}

Some values are presented as mean \pm S.D., and statistical analyses were performed by one-way ANOVA. $P<0.05$ was considered to be statistically significant. SPE, severe preeclampsia; SGA, small for gestational age; NS, not significant. 
sPE had no other maternal complications. The demographic and clinical characteristics of the study groups are summarized in Table 3. The study protocol was approved by the ethics committee of the Institute of Zoology, Chinese Academy of Sciences.

Peripheral blood was collected into EDTAK 2 tubes (San Li, Liuyang, China), and then immediately subjected to centrifugation at $820 \mathrm{~g}$ for $10 \mathrm{~min}$. Supernatant plasma was transferred to RNase-free tubes and centrifuged at $16000 \mathrm{~g}$ for $10 \mathrm{~min}$ to pellet any remaining cellular debris. Aliquots of the supernatant were transferred to fresh tubes and immediately stored at $-80^{\circ} \mathrm{C}$.

\section{Total RNA isolation from human plasma samples}

Total RNA was isolated from $400 \mu$ l human plasma sample with the mirVana PARIS kit (Ambion, Carlsbad, CA, USA) according to the manufacturer's instructions, with the modification that samples were extracted twice with an equal volume of acidphenol:chloroform (Mitchell et al. 2008). Synthetic Caenorhabditis elegans miRNAs, including cel-miR-39, cel-miR-54, and cel-miR-238 (GenePharma, Shanghai, China), were added to each denatured sample (after the addition of an equal volume of $2 \times$ denaturing solution to plasma to inhibit RNases) to normalize variation in RNA isolation from different samples (Mitchell et al. 2008). RNA was eluted with $110 \mu$ l elution solution.

\section{Mature miRNA microarray analysis}

Nine samples, including five sPE plasma samples and four normal pregnancy plasma samples, were analyzed by Agilent miRNA microarray chips (ShanghaiBio Corporation, Shanghai, China). Raw data were normalized with GeneSpring 11.2 software (Agilent Technologies, Santa Clara, CA, USA).
miRNAs with significantly $(P<0.05)$ differential expression of twofold changes or more were screened by Student's $t$-test for unpaired heteroscedastic samples without adjustment of $P$ values.

\section{Real-time quantitative stem-loop RT-PCR validation of mature miRNA microarray}

miRNAs with significantly $(P<0.05)$ differential expression of twofold changes or more were further validated in 19 plasma samples by real-time stem-loop qRT-PCR as described previously (Chen et al. 2005, Varkonyi-Gasic et al. 2007) with some modifications. In brief, a 'no RNA' RT master mix was first prepared by scaling the volume of each reaction that contained $0.5 \mu \mathrm{l} 10 \mathrm{mM}$ dNTP mix, $10.15 \mu \mathrm{l}$ nuclease-free water, and $1 \mu \mathrm{l}$ stem-loop RT primer $(1 \mu \mathrm{M})$. The mixture was heated at $65{ }^{\circ} \mathrm{C}$ for $5 \mathrm{~min}$ and incubated on ice for $2 \mathrm{~min}$. After a brief centrifugation, $4 \mu \mathrm{l} 5 \times$ first-strand buffer, $2 \mu \mathrm{l} 0.1 \mathrm{M}$ DTT, $0.1 \mu \mathrm{l}$ RNase inhibitor (40 units/ $\mu \mathrm{l}$, TaKaRa Biotechnology, Dalian, China), and $0.25 \mu \mathrm{l}$ SuperScript II RT (200 units/ $\mu$ l, Invitrogen) were added into the mixture for each reaction. The RT master mix was then aliquoted to each reaction $(18 \mu \mathrm{l})$, into which $2 \mu \mathrm{l}$ RNA isolated from human plasma sample with spiked-in $C$. elegans control miRNAs was added. Stem-loop RT reactions were performed at $16{ }^{\circ} \mathrm{C}$ for $30 \mathrm{~min}, 42^{\circ} \mathrm{C}$ for $30 \mathrm{~min}$, and $85^{\circ} \mathrm{C}$ for $5 \mathrm{~min}$ and then held at $4{ }^{\circ} \mathrm{C}$.

Real-time PCR was performed by a standard SYBR Premix Ex Taq II (Perfect Real Time) (TaKaRa Biotechnology) kit protocol. The $20 \mu \mathrm{l}$ PCR consists of $10 \mu \mathrm{l}$ SYBR Premix Ex Taq II $(2 \times)$, $1 \mu \mathrm{l}$ PCR forward primer $(10 \mu \mathrm{M}), 1 \mu \mathrm{l}$ PCR reverse primer $(10 \mu \mathrm{M}), 2 \mu \mathrm{l}$ stem-loop RT product, and $6 \mu \mathrm{l} \mathrm{dH}_{2} \mathrm{O}$. The reactions were incubated at $95{ }^{\circ} \mathrm{C}$ for $30 \mathrm{~s}$, followed by 45 cycles of $95{ }^{\circ} \mathrm{C}$ for $5 \mathrm{~s}, 60^{\circ} \mathrm{C}$ for $10 \mathrm{~s}$, and $72{ }^{\circ} \mathrm{C}$ for $25 \mathrm{~s}$, and then ended by a melting step with slow heating from 65 to $95{ }^{\circ} \mathrm{C}$. All reactions were done in duplicate. The threshold

Table 4 Primers used in real-time quantitative stem-loop RT-PCR analysis.

\begin{tabular}{|c|c|c|}
\hline miRNAs & Primers & Sequence $\left(5^{\prime}-3^{\prime}\right)$ \\
\hline \multirow[t]{2}{*}{ hsa-miR-24 } & RT & GTCGTATCCAGTGCAGGGTCCGAGGTATTCGCACTGGATACGACCTGTTC \\
\hline & PCR & GCGTGGCTCAGTTCAGCAG \\
\hline \multirow[t]{2}{*}{ hsa-miR-26a } & RT & GTCGTATCCAGTGCAGGGTCCGAGGTATTCGCACTGGATACGACAGCCTA \\
\hline & PCR & GGCAGGTTCAAGTAATCCAGGA \\
\hline \multirow[t]{2}{*}{ hsa-miR-103 } & RT & GTCGTATCCAGTGCAGGGTCCGAGGTATTCGCACTGGATACGACTCATAG \\
\hline & PCR & GGCAGCAGCATTGTACAGGG \\
\hline \multirow[t]{2}{*}{ hsa-miR-130b } & RT & GTCGTATCCAGTGCAGGGTCCGAGGTATTCGCACTGGATACGACATGCCC \\
\hline & PCR & GCCGCCAGTGCAATGATGAAA \\
\hline \multirow[t]{2}{*}{ hsa-miR-181a } & RT & GTCGTATCCAGTGCAGGGTCCGAGGTATTCGCACTGGATACGACACTCAC \\
\hline & PCR & GCCGAACATTCAACGCTGTCG \\
\hline \multirow[t]{2}{*}{ hsa-miR-342-3p } & RT & GTCGTATCCAGTGCAGGGTCCGAGGTATTCGCACTGGATACGACACGGGT \\
\hline & PCR & GGCTCTCACACAGAAATCGC \\
\hline \multirow[t]{2}{*}{ hsa-miR-574-5p } & RT & GTCGTATCCAGTGCAGGGTCCGAGGTATTCGCACTGGATACGACACACAC \\
\hline & PCR & CCGCTGAGTGTGTGTGTGTGA \\
\hline \multirow[t]{2}{*}{ cel-miR-39 } & RT & GTCGTATCCAGTGCAGGGTCCGAGGTATTCGCACTGGATACGACCAAGCT \\
\hline & PCR & GCGCTCACCGGGTGTAAATC \\
\hline \multirow[t]{2}{*}{ cel-miR-54 } & RT & GTCGTATCCAGTGCAGGGTCCGAGGTATTCGCACTGGATACGACCTCGGA \\
\hline & PCR & GGCCGTACCCGTAATCTTCATAA \\
\hline \multirow[t]{2}{*}{ cel-miR-238 } & RT & GTCGTATCCAGTGCAGGGTCCGAGGTATTCGCACTGGATACGACTCTGAA \\
\hline & PCR & GGCGTTTGTACTCCGATGCCA \\
\hline Universal reverse & PCR & GTGCAGGGTCCGAGGT \\
\hline
\end{tabular}

hsa, Homo sapiens; cel, Caenorhabditis elegans. 
cycle $\left(C_{t}\right)$ refers to the fractional cycle number at which the fluorescence passes the fixed threshold. In this study, the $C_{\mathrm{t}}$ was determined with the automatic threshold settings. The 'Deltadelta' method (Livak \& Schmittgen 2001) was used to analyze real-time qRT-PCR data. Normalization of experimental realtime qRT-PCR data using spiked-in $C$. elegans control miRNAs was carried out as described previously (Mitchell et al. 2008). All primers synthesized by Invitrogen, Beijing, China are listed in Table 4.

\section{Statistical analysis}

Validation results from real-time qRT-PCR are displayed as the mean \pm s.D. Statistical analysis was performed by oneway ANOVA. $P<0.05$ was considered to be statistically significant.

\section{GO and pathway enrichment analyses}

Differentially expressed miRNAs were further analyzed for predicted targets from TargetScan (www.targetscan.org) via GeneSpring 11.2 software, while the parameters were set as 'context score percentile: 90.0 ' and 'database: conserved'. GO and pathway enrichment analyses of predicted targets of the differentially expressed miRNAs were undertaken by the ShanghaiBio Corporation (SBC) analysis system (http://sas. ebioservice.com), which functions on the enrichment calculation and function annotation of differentially expressed genes by combining R-software (the $\mathrm{R}$ Project for Statistical Computing, http://www.r-project.org) with seven public databases that include NCBI Entrez Gene (http://www.ncbi.nlm. nih.gov/gene), GO (http://www.geneontology.org), KEGG (http://www.genome.jp/kegg), and Biocarta (http://www. biocarta.com). The enrichment $P$ values of both $\mathrm{GO}$ and pathway enrichment analyses were calculated by Fisher's exact test (Fisher 1922), which were corrected by enrichment $q$-values (the false discovery rate) that were calculated by John Storey's method (Storey et al. 2004).

\section{Declaration of interest}

The authors declare that there is no conflict of interest that could be perceived as prejudicing the impartiality of the research reported.

\section{Funding}

This study was supported by the National Key Basic Research Program of China (2011CB944403), the National Basic Research Program of China (973 Program) (2010CB535015), and the Knowledge Innovation Program in the Chinese Academy of Sciences (KSCX2-EW-R-06).

\section{Acknowledgements}

We are thankful to Dr Jimeng Wang (Department of Obstetrics and Gynecology, General Hospital of the People's Liberation Army in Beijing, China) for clinical sample collection, and to
Dr Xiaoyan Lin (ShanghaiBio Corporation in Shanghai, China) for helpful assistance in GO and pathway enrichment analyses using the SBC analysis system.

\section{References}

Ali KZ 1997 Stereological study of the effect of altitude on the trophoblast cell populations of human term placental villi. Placenta 18 447-450. (doi:10.1016/S0143-4004(97)80046-X)

Barad O, Meiri E, Avniel A, Aharonov R, Barzilai A, Bentwich I, Einav U, Gilad S, Hurban P, Karov Y et al. 2004 MicroRNA expression detected by oligonucleotide microarrays: system establishment and expression profiling in human tissues. Genome Research 14 2486-2494. (doi:10. 1101/gr.2845604)

Bartel DP 2004 MicroRNAs: genomics, biogenesis, mechanism, and function. Cell 116 281-297. (doi:10.1016/S0092-8674(04)00045-5)

Bloxam DL, Bullen BE, Walters BN \& Lao TT 1987 Placental glycolysis and energy metabolism in preeclampsia. American Journal of Obstetrics and Gynecology 157 97-101.

Bonney EA 2007 Preeclampsia: a view through the danger model. Journal of Reproductive Immunology 76 68-74. (doi:10.1016/j.jri.2007.03.006)

Chen CF, Ridzon DA, Broomer AJ, Zhou ZH, Lee DH, Nguyen JT, Barbisin M, Xu NL, Mahuvakar VR, Andersen MR et al. 2005 Real-time quantification of microRNAs by stem-loop RT-PCR. Nucleic Acids Research 33 e179. (doi:10.1093/nar/gni178)

Cheng W, Liu T, Jiang F, Liu C, Zhao X, Gao Y, Wang H \& Liu Z 2011 microRNA-155 regulates angiotensin II type 1 receptor expression in umbilical vein endothelial cells from severely pre-eclamptic pregnant women. International Journal of Molecular Medicine 27 393-399. (doi:10.3892/ijmm.2011.598)

Chim SS, Shing TK, Hung EC, Leung TY, Lau TK, Chiu RW \& Lo YM 2008 Detection and characterization of placental microRNAs in maternal plasma. Clinical Chemistry 54 482-490. (doi:10.1373/clinchem.2007. 097972)

Enquobahrie DA, Abetew DF, Sorensen TK, Willoughby D, Chidambaram K \& Williams MA 2011 Placental microRNA expression in pregnancies complicated by preeclampsia. American Journal of Obstetrics and Gynecology 204178 e12-e21. (doi: 10.1016/j.ajog.2010.09.004)

Fisher RA 1922 On the interpretation of $\chi 2$ from contingency tables, and the calculation of P. Journal of the Royal Statistical Society 85 87-95. (doi:10. 2307/2340521)

Fox H 1964 The villous cytotrophoblast as an index of placental ischaemia. Journal of Obstetrics and Gynaecology of the British Commonwealth $\mathbf{7 1}$ 885-893. (doi:10.1111/j.1471-0528.1964.tb04375.x)

Genbacev O, Joslin R, Damsky CH, Polliotti BM \& Fisher SJ 1996 Hypoxia alters early gestation human cytotrophoblast differentiation/invasion in vitro and models the placental defects that occur in preeclampsia. Journal of Clinical Investigation 97 540-550. (doi:10.1172/JCI118447)

Gilad S, Meiri E, Yogev Y, Benjamin S, Lebanony D, Yerushalmi N, Benjamin H, Kushnir M, Cholakh H, Melamed N et al. 2008 Serum microRNAs are promising novel biomarkers. PLOS ONE 3 e3148. (doi:10.1371/journal.pone.0003148)

Hogberg U 2005 The World Health Report 2005: "make every mother and child count" - including Africans. Scandinavian Journal of Public Health 33 409-411. (doi:10.1080/14034940500217037)

Hu Y, Li P, Hao S, Liu L, Zhao J \& Hou Y 2009 Differential expression of microRNAs in the placentae of Chinese patients with severe preeclampsia. Clinical Chemistry and Laboratory Medicine 47 923-929. (doi:10.1515/CCLM.2009.228)

Huppertz B \& Peeters LL 2005 Vascular biology in implantation and placentation. Angiogenesis 8 157-167. (doi:10.1007/s10456-0059007-8)

Ji J, Yamashita T, Budhu A, Forgues M, Jia HL, Li C, Deng C, Wauthier E, Reid LM, Ye QH et al. 2009 Identification of microRNA-181 by genomewide screening as a critical player in EpCAM-positive hepatic cancer stem cells. Hepatology 50 472-480. (doi:10.1002/hep.22989)

Kulshreshtha R, Ferracin M, Wojcik SE, Garzon R, Alder H, AgostoPerez FJ, Davuluri R, Liu CG, Croce CM, Negrini M et al. 2007 A microRNA signature of hypoxia. Molecular and Cellular Biology 27 1859-1867. (doi:10.1128/MCB.01395-06) 
Lal A, Navarro F, Maher CA, Maliszewski LE, Yan N, O'Day E, Chowdhury D, Dykxhoorn DM, Tsai P, Hofmann O et al. 2009 miR-24 Inhibits cell proliferation by targeting E2F2, MYC, and other cell-cycle genes via binding to "seedless" $3^{\prime} U T R$ microRNA recognition elements. Molecular Cell 35 610-625. (doi:10.1016/j.molcel. 2009.08.020)

Levine RJ, Lam C, Qian C, Yu KF, Maynard SE, Sachs BP, Sibai BM, Epstein FH, Romero R, Thadhani R et al. 2006 Soluble endoglin and other circulating antiangiogenic factors in preeclampsia. New England Journal of Medicine 355 992-1005. (doi:10.1056/NEJMoa 055352)

Lewis BP, Burge CB \& Bartel DP 2005 Conserved seed pairing, often flanked by adenosines, indicates that thousands of human genes are microRNA targets. Cell 120 15-20. (doi:10.1016/j.cell.2004.12.035)

Li QJ, Chau J, Ebert PJ, Sylvester G, Min H, Liu G, Braich R, Manoharan M, Soutschek J, Skare P et al. 2007 miR-181a is an intrinsic modulator of T cell sensitivity and selection. Cell 129 147-161. (doi:10.1016/j.cell. 2007.03.008)

Liang Y, Ridzon D, Wong L \& Chen C 2007 Characterization of microRNA expression profiles in normal human tissues. BMC Genomics 8166. (doi:10.1186/1471-2164-8-166)

Livak KJ \& Schmittgen TD 2001 Analysis of relative gene expression data using real-time quantitative PCR and the $2(-$ Delta Delta $C(\mathrm{~T}))$ method. Methods 25 402-408. (doi:10.1006/meth.2001.1262)

Lu J, He ML, Wang L, Chen Y, Liu X, Dong Q, Chen YC, Peng Y, Yao KT, Kung HF et al. 2011 MiR-26a inhibits cell growth and tumorigenesis of nasopharyngeal carcinoma through repression of EZH2. Cancer Research 71 225-233. (doi:10.1158/0008-5472.CAN-10-1850)

Ma S, Tang KH, Chan YP, Lee TK, Kwan PS, Castilho A, Ng I, Man K, Wong N, To KF et al. 2010 miR-130b promotes CD133(+) liver tumorinitiating cell growth and self-renewal via tumor protein 53-induced nuclear protein 1. Cell Stem Cell 7 694-707. (doi:10.1016/j.stem.2010. 11.010)

Martello G, Rosato A, Ferrari F, Manfrin A, Cordenonsi M, Dupont S, Enzo E, Guzzardo V, Rondina M, Spruce T et al. 2010 A microRNA targeting dicer for metastasis control. Cell 141 1195-1207. (doi:10.1016/ j.cell.2010.05.017)

Maynard S, Epstein FH \& Karumanchi SA 2008 Preeclampsia and angiogenic imbalance. Annual Review of Medicine 59 61-78. (doi:10. 1146/annurev.med.59.110106.214058)

Mayor-Lynn K, Toloubeydokhti T, Cruz AC \& Chegini N 2011 Expression profile of microRNAs and mRNAs in human placentas from pregnancies complicated by preeclampsia and preterm labor. Reproductive Sciences 18 46-56. (doi:10.1177/1933719110374115)

Mitchell PS, Parkin RK, Kroh EM, Fritz BR, Wyman SK, PogosovaAgadjanyan EL, Peterson A, Noteboom J, O'Briant KC, Allen A et al. 2008 Circulating microRNAs as stable blood-based markers for cancer detection. PNAS 105 10513-10518. (doi:10.1073/pnas.08045 49105)

Myatt L 2002 Role of placenta in preeclampsia. Endocrine 19 103-111. (doi:10.1385/ENDO:19:1:103)

Noack F, Ribbat-Idel J, Thorns C, Chiriac A, Axt-Fliedner R, Diedrich K \& Feller AC 2011 miRNA expression profiling in formalin-fixed and paraffin-embedded placental tissue samples from pregnancies with severe preeclampsia. Journal of Perinatal Medicine 39 267-271. (doi:10.1515/JPM.2011.012)

Oliveras-Ferraros C, Cufi S, Vazquez-Martin A, Torres-Garcia VZ, Del Barco S, Martin-Castillo B \& Menendez JA 2011 Micro(mi)RNA expression profile of breast cancer epithelial cells treated with the antidiabetic drug metformin: induction of the tumor suppressor miRNA let$7 \mathrm{a}$ and suppression of the TGFbeta-induced oncomiR miRNA-181a. Cell Cycle 10 1144-1151. (doi:10.4161/cc.10.7.15210)

Pineles BL, Romero R, Montenegro D, Tarca AL, Han YM, Kim YM, Draghici S, Espinoza J, Kusanovic JP, Mittal P et al. 2007 Distinct subsets of microRNAs are expressed differentially in the human placentas of patients with preeclampsia. American Journal of Obstetrics and Gynecology 196261 e261-e266. (doi: 10.1016/j.ajog.2007.01.008)

Practice ACoO 2002 ACOG practice bulletin. Diagnosis and management of preeclampsia and eclampsia. Number 33, January 2002. American College of Obstetricians and Gynecologists. Obstetrics \& Gynecology 99 159-167. (doi:10.1016/S0029-7844(01)01747-1)
Rajakumar A, Brandon HM, Daftary A, Ness R \& Conrad KP 2004 Evidence for the functional activity of hypoxia-inducible transcription factors overexpressed in preeclamptic placentae. Placenta 25 763-769. (doi:10. 1016/j.placenta.2004.02.011)

Ranade AR, Cherba D, Sridhar S, Richardson P, Webb C, Paripati A, Bowles B \& Weiss GJ 2010 MicroRNA 92a-2*: a biomarker predictive for chemoresistance and prognostic for survival in patients with small cell lung cancer. Journal of Thoracic Oncology 5 1273-1278. (doi:10.1097/ JTO.0b013e3181dea6be)

Roman A, Ahn HW, Qi Z, Zhou X, Gao X \& Rajkovic A 2008 237: MicroRNA expression in placenta of patients with preeclampsia. American Journal of Obstetrics and Gynecology 199 S78. (doi:10. 1016/j.ajog.2008.09.265)

Ronchetti D, Lionetti M, Mosca L, Agnelli L, Andronache A, Fabris S, Deliliers GL \& Neri A 2008 An integrative genomic approach reveals coordinated expression of intronic miR-335, miR-342, and miR-561 with deregulated host genes in multiple myeloma. BMC Medical Genomics 1 37. (doi:10.1186/1755-8794-1-37)

Saba R, Goodman CD, Huzarewich RL, Robertson C \& Booth SA 2008 A miRNA signature of prion induced neurodegeneration. PLOS ONE 3 e3652. (doi:10.1371/journal.pone.0003652)

Saito K, Kondo E \& Matsushita M 2011 MicroRNA 130 family regulates the hypoxia response signal through the P-body protein DDX6. Nucleic Acids Research 39 6086-6099. (doi:10.1093/nar/gkr194)

Sander S, Bullinger L, Klapproth K, Fiedler K, Kestler HA, Barth TF, Moller P, Stilgenbauer S, Pollack JR \& Wirth T 2008 MYC stimulates EZH2 expression by repression of its negative regulator miR-26a. Blood 112 4202-4212. (doi:10.1182/blood-2008-03-147645)

Semenza GL \& Wang GL 1992 A nuclear factor induced by hypoxia via de novo protein synthesis binds to the human erythropoietin gene enhancer at a site required for transcriptional activation. Molecular and Cellular Biology 12 5447-5454.

Sibai B, Dekker G \& Kupferminc M 2005 Pre-eclampsia. Lancet 365 785-799. (doi: 10.1016/S0140-6736(05)17987-2)

Storey JD, Taylor JE \& Siegmund D 2004 Strong control, conservative point estimation, and simultaneous conservative consistency of false discovery rates: a unified approach. Journal of the Royal Statistical Society, Series B 66 187-205. (doi:10.1111/j.1467-9868.2004.00439.x)

Su X, Chakravarti D, Cho MS, Liu L, Gi YJ, Lin YL, Leung ML, El-Naggar A, Creighton CJ, Suraokar MB et al. 2010 TAp63 suppresses metastasis through coordinate regulation of Dicer and miRNAs. Nature 467 986-990. (doi:10.1038/nature09459)

Tranquilli AL \& Landi B 2010 The origin of pre-eclampsia: from decidual "hyperoxia" to late hypoxia. Medical Hypotheses 75 38-46. (doi:10. 1016/j.mehy.2010.01.024)

Van der Auwera I, Limame R, van Dam P, Vermeulen PB, Dirix LY \& Van Laere SJ 2010 Integrated miRNA and mRNA expression profiling of the inflammatory breast cancer subtype. British Journal of Cancer 103 532-541. (doi:10.1038/sj.bjc.6605787)

Varkonyi-Gasic E, Wu R, Wood M, Walton EF \& Hellens RP 2007 Protocol: a highly sensitive RT-PCR method for detection and quantification of microRNAs. Plant Methods 3 12. (doi:10.1186/1746-4811-3-12)

Walsh SW \& Wang Y 1993 Deficient glutathione peroxidase activity in preeclampsia is associated with increased placental production of thromboxane and lipid peroxides. American Journal of Obstetrics and Gynecology 169 1456-1461.

Wang GL, Jiang BH, Rue EA \& Semenza GL 1995 Hypoxia-inducible factor 1 is a basic-helix-loop-helix-PAS heterodimer regulated by cellular $\mathrm{O}_{2}$ tension. PNAS 92 5510-5514. (doi:10.1073/pnas.92.12.5510)

Wang Q, Huang Z, Xue H, Jin C, Ju XL, Han JD \& Chen YG 2008 MicroRNA miR-24 inhibits erythropoiesis by targeting activin type I receptor ALK4. Blood 111 588-595. (doi:10.1182/blood-2007-05-092718)

Wang K, Zhang S, Marzolf B, Troisch P, Brightman A, Hu Z, Hood LE \& Galas DJ 2009 Circulating microRNAs, potential biomarkers for drug-induced liver injury. PNAS 106 4402-4407. (doi:10.1073/pnas.0813371106)

Wu F, Yang Z \& Li G 2009 Role of specific microRNAs for endothelial function and angiogenesis. Biochemical and Biophysical Research Communications 386 549-553. (doi:10.1016/j.bbrc.2009.06.075)

Yeung ML, Yasunaga J, Bennasser Y, Dusetti N, Harris D, Ahmad N, Matsuoka M \& Jeang KT 2008 Roles for microRNAs, miR-93 and miR$130 \mathrm{~b}$, and tumor protein 53-induced nuclear protein 1 tumor suppressor 
in cell growth dysregulation by human T-cell lymphotrophic virus 1 . Cancer Research 68 8976-8985. (doi:10.1158/0008-5472.CAN-080769)

Zaidi SK, Dowdy CR, van Wijnen AJ, Lian JB, Raza A, Stein JL, Croce CM \& Stein GS 2009 Altered Runx1 subnuclear targeting enhances myeloid cell proliferation and blocks differentiation by activating a miR-24/MKP7/MAPK network. Cancer Research 69 8249-8255. (doi:10.1158/00085472.CAN-09-1567)

Zhang Y, Diao Z, Su L, Sun H, Li R, Cui H \& Hu Y 2010 MicroRNA-155 contributes to preeclampsia by down-regulating CYR61. American Journal of Obstetrics and Gynecology 466 e461-e467. (doi: 10.1016/ j.ajog.2010.01.057)
Zhu XM, Han T, Sargent IL, Yin GW \& Yao YQ 2009 Differential expression profile of microRNAs in human placentas from preeclamptic pregnancies vs normal pregnancies. American Journal of Obstetrics and Gynecology 661 e661-e667. (doi: 10.1016/j.ajog.2008.12.045)

Received 17 August 2011

First decision 9 September 2011

Revised manuscript received 9 December 2011

Accepted 20 December 2011 